\title{
Special Education Professionalism: The Catalyst for Optimum Learning of Individuals with Exceptionalities
}

\author{
Richard W. Mainzer, Jr. \\ Mainzer Consulting Services \\ Alexandria, Virginia, USA
}

\author{
Lynne Harper Mainzer \\ Johns Hopkins University \\ Center for Technology in Education \\ Columbia MD, USA
}

\begin{abstract}
The concept of professionalism in special education is examined as the essential catalyst for optimal learning of children with exceptionalities, and posits that professionalism in special education must be the guide for policy issues The significance of professionalism in special education is based on the premise that optimum learning for persons with exceptionalities which in turn depends a strong cadre of career-oriented special education professionals. In turn, the privileges granted to professional special educators require they uphold high standards of practice. Implications for special and general education teacher preparation are analyzed. The authors use the literature and policy along with their depth of experience with professional standards to delineate the characteristics of professionalism and apply each to special education.
\end{abstract}

\section{Introduction}

Inclusion for individuals with disabilities has been a compelling educational policy issue for some time now [1]. However, the recent UNESCO report, Fixing Broken Promises, (2015) [2] makes clear that children with disabilities are too often critically underserved or excluded from education altogether because systems do not have the resources including special education professionals. For far too long policymakers have opted for cheap quick fix solutions and even strategies of blame.

The effective inclusion of individuals with exceptionalities in schools and to learning is a complex policy issue that requires policymakers to contextualize the issue of inclusion within a more fundamental focus on the infrastructure of education as a profession. An essential component of this infrastructure is well-prepared and qualified professional special educators from a variety of specializations with the appropriate resources and professional freedom to personalize the appropriate instruction and supports for each individual with an exceptionality.

It is the perspective of this article that, if policymaking bodies desire effective inclusion of individuals with exceptionalities in learning and school environments, they must refocus their reform efforts toward supporting special educators establishing special education as a mature profession.

This paper examines the concept of professionalism in special education as the catalyst for optimal learning of children with exceptionalities, and posits that professionalism in special education should be the overriding guide for policy issues such as inclusion.

\section{Professionalism}

The Merriam-Webster Dictionary [3] indicates the first recorded use of "professional" was in the early fifteenth century, referring to "pertaining or making entrance into a religious order." If we look at the root word "profess", the OED notes that "before 1500" the word was used "only in a religious sense," having the meaning "To have made one's profession in religion." Early use of "professional" connoted a commitment to a certain way of life. To "profess" meant to be received formally into a specialized community such as a religious monk who takes monastic vows in a religious order. It implied a public avowal to follow a path of high moral ideals.

By the late seventeenth century, the word became more secular in meaning and expanded beyond religion. "Professional" included those who were qualified to pursue a vocation or calling. Not until the early eighteenth century does profession take on its more modern meaning, "pertaining to, proper to, or connected with one's profession or calling."

The modern use of term professional is actually relatively recent. In the early nineteenth century law and medicine began to be recognized as professions because they required "professed" specialized 
knowledge, shared values and wisdom, and a relationship of trust with others.

However, two of the most well-established professions, medicine and law had no standard certification or corpus of agreed upon standards at this time. President Abraham Lincoln, a lawyer, did not attend law school, serve as an apprentice, or even take a Bar Exam. Lincoln became a lawyer under an 1833 Illinois law with its only requirement was to "obtain a certificate procured from the court of an Illinois county certifying to the applicant's good moral character."

Additionally, in medicine it was not until the Flexner Report in 1910 that the medical profession in the U.S. widely accepted science as a basis for the development of medical standards for the preparation of doctors [4].

In the U.S. the application to educators of the concept of professionalism dates back at least to 1913 when John Dewey compared the American Association of University Professors (AAUP) to the American Bar Association and the American Medical Association reflecting that the professoriate would become a self-governing profession [5]. Like medicine and law, establishing education as a profession has not been direct in the U.S. As a female dominated profession with the need for ever greater numbers of teachers, educators found it difficult to develop and maintain professional standards and establish themselves as recognized professionals.

Teacher certification in the nineteenth century was irregular and diverse. There was no single pattern, and there was no teaching profession as such. Similarly, in the first half of the nineteenth century, the requirements for entry into teaching were modest: new teachers had to persuade a local school board of their moral character, and in some districts, pass a test of their general knowledge [6]. In 1834, Pennsylvania became the first state to require future teachers to pass a test of reading, writing, and arithmetic. By 1867 , most states required teachers to pass a locally administered test to get a state certificate, which usually included not only the basic skills, but also U.S. history, geography, spelling, and grammar.

During the nineteenth century, different states in the United States adopted different approaches to training future teachers. In some, like New York, the state subsidized private academies to prepare teachers. Massachusetts supported "normal schools" for teacher training, which offered short courses in educational methods, mainly for elementary teachers. In western states, normal schools offered longer courses, both academic and professional, which prepared future teachers and administrators. In rural areas, local school boards ran teacher institutes, where their teachers could brush up on academic and pedagogical subjects. Some large school districts, like New York City, organized their own teacher training programs, led by experienced teachers, well into the 1930s.

This changed, however, at the beginning of the twentieth century during the second great immigration wave in the United States. In this immigration wave were a large proportion of children who did not speak English as a primary language as well as children from cultures alien to many American teachers. The question of how to teach these children came into focus.

It was also during the turn of the twentieth century, schools of education expanded into undergraduate and graduate schools of education where both pedagogy and subject matter were be studied. These colleges began specializations in such as school administration, educational psychology, educational sociology, curriculum, and special education. Experts and professionals began creating an education profession with its own preparation programs and its own professional standards.

It is noteworthy that Council for Exceptional Children (CEC) was created at Teachers College Columbia University which was one of the earliest institutions to address pedagogy. From its creation CEC recognized the significance of connections between professional standards and quality special educators on the learning of individuals with exceptionalities ${ }^{1}$. At the first meeting of CEC in 1922, the establishment of professional standards for teachers in the field of special education was identified as one of the primary aims of CEC.

Even today CEC develops standards and processes to ensure that special educators are prepared to practice effectively and ethically. CEC develops preparation standards, ethical, and practice guidelines to ensure that all credentialed special education professionals are responsible and accountable for practicing in compliance with the ethics and standards of the profession [7].

\section{Characteristics of Professions}

Individuals in mature professions view themselves as well-prepared career-oriented members of an elite group. Contemporary discussions of professions most often include characteristics such as a validated corpus of specialized knowledge and skills,

\footnotetext{
As used herein, individuals with exceptionalities include individuals with sensory, physical, emotional, social, cognitive differences, developmentally delays, exceptional gifts and talents; and individuals who are or have been abused or neglected; whose needs differ so as to require personalized special education services in addition to or in tandem with educational services available through general education programs and other human service delivery systems.
} 
preparation programs with clinical experiences that are designed to prepare candidates to master the specialized knowledge and skills, credentials from the jurisdiction of practice that recognizes the professional, and a commitment to the individuals served by the professionals along with the recognition of the need to practice ethically and to updating of skills throughout the career. Next we examine each and highlight related issues for education and special education.

\subsection{Specialized Knowledge and Skill}

Professions are based on specialized knowledge and skill based in science $[8,9]$. The expertise of the professional stems from mastery of the application of a body of knowledge and skills that are specialized and often abstract and theoretical, requiring lengthy preparatory instruction in the underlying scientific and historical principles. Professional associations typically are responsible for defining the knowledge and skill required for acceptance into the profession and dividing them into their areas of specialization.

On behalf of special education professionals, CEC develops rigorously validated standards and processes to ensure that special educators master the specialized knowledge and skill based in science and are prepared to practice effectively and ethically.

Ethical and professional standards of practice have been validated by CEC and address issues of:

- Preparation and Credentialing Ensuring that professionals have mastered the specialized skills and knowledge and engage in scientifically-based skilled practice, and

Assuring only properly qualified members are recognized to practice and that they do so according to professional standards

- $\quad$ Ethics and Practice Guidelines Guiding professionals in protecting individuals with exceptionalities and the public from unethical and/or incompetent practice

- Continuing competence Pursuing personal professional development and adherence to standards and guidelines in all areas of professional practice

\subsection{Preparation Programs with Induction and Credentialing}

Professionals are prepared through a recognized preparation program including knowledge, skills, and clinical practice. Professionals agree on performance standards for admission to the profession and for continuance within it. They also undergo external examination to assure they possess the specialized knowledge and skill to practice safely and effectively prior to beginning professional practice.

Professionals derive authority and relative autonomy to practice through a publically granted credential from the governmental jurisdiction in which they will practice.

Additionally, professionals are members of one or more professional associations that have a degree of autonomy in control of the work of the profession and the conditions that contextualize it.

A key expectation of members of self-governing professions is that the professional accepts both legal and ethical accountability for their work and hold the interest of the public and society paramount. This not only protects the society to which the professional provides specialized services, but importantly encourages pride of workmanship, productivity, individual responsibility, self-discipline, ethical standards, and public interest.

Over the past three decades, a great deal of interest has focused on upgrading the education, preparation, and training requirements for teachers. Research has shown moderate but consistent support for the reasonable proposition that subject knowledge (knowing what to teach) and teaching skills (knowing how to teach) are important predictors of both teaching quality and student learning (for reviews of this research [10].

Knowledge of subject matter and of pedagogical methods are necessary but not sufficient for qualified teachers. In this view, efforts to tighten entry-level standards for newly hired teachers, and efforts to insure that teachers only teach subjects for which they have minimal training, would help insure that educators possess expertise over the bodies of knowledge they will teach [11].

In the last two decades, many countries, including Australia, France, Finland, Germany, Hong Kong, Ireland, Italy, Luxembourg, the Netherlands, New Zealand, Portugal, and Taiwan have moved most teacher education to the graduate level, adding indepth pedagogical study and an intensive internship or practicum in schools to a base of strong undergraduate preparation in the disciplines. Furthermore, teaching shortages are rare in countries where teacher salaries are competitive with those in other professional occupations. [12]

Education as a profession has not been without detractors. In fact, many of the current education reform policies appear to intentionally detract from the professionalization of educators. Milner et al discuss how three recent popular educational reform policies move teaching away from professionalization. These reforms are (1) policies that evaluate teachers based on individuals with exceptionalities' annual standardized test score gains, 
and specifically, those based on value-added assessment; (2) fast-track teacher preparation and licensure; and (3) scripted, narrowed curricula [13].

They conclude that these three reforms, on the whole, lower the professional status of teaching. The pattern is nuanced, however. For instance, valueadded teacher evaluation policies are deprofessionalizing: pressuring teachers to mechanically teach to tests while systematically devaluing the broader yet essential elements of teaching. Alternative, fast-track teacher preparation programs, such as Teach for America, purport to recruit from academic elites, its advocates view as a step towards professionalization.

However, fast-track teacher preparation and licensure programs de-professionalize teaching by the lack of focus on pedagogical training, the small amount of time dedicated to preparing teachers to teach, the assignment of inexperienced personnel to the most challenging schools, and the itinerate nature of these teachers.

Many jurisdictions have implemented initiatives to increase special educators from non-traditional or non-accredited educational programs [14]. These initiatives include, but are not limited to starting the licensing process prior to completion of professional preparation, facilitating the attainment of experience through co-operative placements or provisional licensure, and creating categories of licensure with limited scopes of practice.

Scripted and narrowed curriculum moves teaching away from professionalization by not allowing teachers to rely on their professional judgment to make curricula decisions for student learning with the consequent sacrifice of higher-level learning, creativity, flexibility, and breadth of learning.

\subsection{Commitment to Lifelong Study}

Becoming a professional special educator is a career choice rather than a temporary stopover after college and prior to starting a "real career." As special educators progress in their teaching careers, many seek to develop and deepen their skills and broaden their knowledge base through advanced study in classroom or specialty areas. Others choose to pursue new roles within special education or to move to administration or higher education.

Regardless of the career path, it is essential for professionals to engage in lifelong learning. Professional standards reflect the dynamic science upon which they are based. The sustained study of professional ethics and specialized issues may be accomplished by reading journals or attending specialized courses, seminars, and conferences. Professionals identify with the professed body of knowledge and are willing to expend time and energy to keep up to date with it, promote its growth, expansion, development, and use in the service of society. Special education professionals also identify with other members of the profession, and peer review, peer approval of demonstrated expertise, and commitment to the profession is a significant source of satisfaction and pride.

Further, the demonstration of continuing expertise fulfills the increasing demands from the public for greater accountability. The standard established for continued competence for each discipline is normally determined by a reasonable and competent group of peers. The standard is dynamic and changes over time as new techniques, practices, and materials are accepted.

In order to retain special educators within education there must be career-oriented pathways for advancement and leadership both within and outside the classroom. Over the last decade CEC has expanded the Special Education Advanced Preparation Standards to encourage teacher leadership and provide special education career matrices

\subsection{Public Trust and Ethical Practice}

It is through the trust of the public that special education professionals are afforded relative autonomy. However, the privilege of being a selfregulated profession is not without responsibility and associated accountability. To protect the public welfare, special education professionals must continually practice to the highest ethical and professional standards.

Professionals are granted a high level of public trust and confidence based on the respect for the profession and the professional's demonstrated capacity to provide service safely and effectively. The public's trust of professions influence how they interact with and rely upon them. Over the last several years in the United States there have been numerous attacks on teachers through misinformation and illconceived policies.

In fact, many of the current education reform policies appear to fragment and weaken the public's trust of educators intentionally, such as unilateral value-added teacher evaluation pressuring teachers to mechanically teach to tests; fast-track teacher preparation and licensure programs that place unprepared personnel in the most challenging schools; and narrowly scripted curriculum that does not allow teachers to rely on their professional judgment to make curricula decisions for student learning.

Special educators recognize that their professionalism is fundamentally based on the 
provision of indispensable interventions for the individuals they serve. Professionals in special education hold paramount the learning, health, safety and welfare of the individuals with exceptionalities they serve, and they welcome valid and fair accountability for their own professional practice, for the professional practice of those under their supervision, and for the profession generally as part of their service. This public-interest disposition takes precedence over self-interest. Protection of the public from unethical and/or incompetent practice is held in the high esteem. CEC's Professional Practice Standards provide interpretation and amplification of the Ethics Principles.

\section{Issues and Opportunities}

\subsection{Recruitment and Retention}

Achieving professionalism depends on resources to recruit and retain strong diverse career-oriented cadres of well-prepared individuals. However, the United States improving of the quality preparation and continuing development of special educators has been overshadowed by three significant variables: a chronic and severe shortage of well-prepared personnel to deliver special education services [15], the unequal distribution of well-prepared special education personnel [16], and working conditions that significantly exacerbate the retention of well-prepared special education personnel [17].

As any special education administrator knows, the shortage of well-prepared special educators creates the terrible dilemma of having to use unqualified personnel. They worry about the negative consequences for the learning of individuals with exceptionalities. They fear the violation of the trust of parents and families.

In addition to recruiting and preparing wellprepared special educators, retention has been made difficult by negative working conditions and policies that are perceived as blaming teachers [18]. The percent of special educators who leave special education each year is almost double the rate of educators in general in the United States. In fact, over half of all entering special educators leave special education before their fifth year of practice. While little data is available regarding the proportion of these leavers who are less than fully-prepared special educators, Rosenberg \& Sindelar have pointed out that it is likely that many of these individuals cycling in and out so quickly are individuals who are not fully prepared and licensed.

If special educators are to continue improving the learning of individuals with exceptionalities a sufficient supply of well-prepared special educators with the conditions that allow them to provide individuals with exceptional needs the most effective interventions, and which encourage entering special educators to become career-oriented special education professionals is imperative.

\subsection{Work Conditions and Policies}

"[One of the] reasons Asian class lessons are so well crafted is that there is a very systematic effort to pass on the accumulated wisdom of teaching practice to each new generation of teachers and to keep perfecting that practice by providing teachers the opportunities to continually learn from each other." [19].

One of the things that the U.S. can learn from other countries is how to build a policy infrastructure that supports reform on a wide scale. Resources are available in U.S. school systems to focus more effectively on improving the quality of teaching, but they need to be redirected toward this end.

Curriculum frameworks must be in places that permit special educators to select the activities and lessons designed for the individual learning of individuals with exceptionalities. In this context educators share a curriculum and a focus for collaboration.

Narrowly scripted curricula design to control teaching does not represent the full range of learning opportunities for all individuals in all locations. Curricula must allow special educators to collaborate with other educators in personalizing learning with challenging learning expectations for every individual with exceptionalities.

Professional educators welcome serious and valid accountability systems. However, test-based policies such as value-added teacher assessment with large error factors are not valid measures the range of skills necessary for effective teaching, and they should be stopped immediately until a satisfactory level of accuracy can be achieved in teacher evaluation systems.

\subsection{Mentoring}

Whenever special educators begin practice in a new specialty area, they should have an induction period working with mentors credentialed and experienced in similar roles. This mentorship is a professional relationship between the new teacher and an experienced teacher that aids the new teacher in further developing knowledge and skills in the area of the credential and provides the support required to sustain the new teacher in practice.

According to CEC, professionals entering initial practice in special education should receive a 
minimum of a 1-year mentorship during the first year of professional special education practice [8]. The mentor should be an experienced professional in the same or a similar role as the individual being mentored who can provide expertise and support on a continuing basis. Even with quality preparation, the beginning special education professional faces new challenges in applying and generalizing newly acquired skills and knowledge. Like other professionals, special educators who have the support of more senior colleagues become proficient more quickly, and are more likely to remain in the profession.

\subsection{Interdisciplinary Preparation and Practice}

One of the significant changes in education over the past several decades is the rapid growth of collaborative educational teams to address the educational needs of individuals. The diversity of the individuals, complexity of curricular demands, growing influence of technology, and the rising targets for learner outcomes in the 21 st century has created the demand for teams of educators collaborating together across disciplines to ensure all individuals are effectively learning challenging curricula.

When education professionals have a culture with a strong service motivation and a commitment to collaboration, they openly share their knowledge and skill across disciplines.

Over the past several decades, the expectations placed on teachers of individuals with exceptionalities have become increasingly broad and complex. In the United States, school-wide systems of support have increased special educators' responsibilities for supporting preventive efforts in general education, and movement to greater inclusion has intensified the need for collaborative relationships with general education colleagues and others [20].

It is important to differentiate the complementary general and special educator skills that lead to integrated collaborative practice from attempts to merge general and special educator skills. To be able to integrate, collaborate, and co-teach productively, the skills and knowledge of general and special educators must complement each other.

The need for special educators to have deep knowledge and skills for direct, intensive, and science-based interventions has grown rather than diminished. Reflective of the personalized needs of individuals with exceptionalities, agencies prepare and credential special educators in a variety of specialty areas. CEC uses a rigorous consensual validation process to identify sets of knowledge and skills for entry-level and advanced special educators in the variety of specialty areas. These specialty sets capture the professional knowledge base, including empirical research, disciplined inquiry, informed theory, and the wisdom of practice for their area of expertise for each proposed knowledge and skill.

There is scant evidence that it is realistic to build a licensure that assumes entry-level professionals can master special educator and general educator knowledge and skills simultaneously.

\subsection{Critical Practice and Science}

Special educators understand special education as an evolving and changing discipline based on philosophies, science-based principles and theories, policies, historical and contemporary points of view that continue to influence the field of special education, and the education of and services for individuals with exceptionalities and their families in both school and society. Special educators understand that these factors influence professional practice, including assessment, instructional planning, implementation, and program evaluation.

Special educators are sensitive to the aspects of diversity with individuals with exceptionalities and their families, how human diversity can influence families, cultures, and schools, and how these complex issues can each interact with the delivery of special education services.

Special educators understand the relationships of the organization of special education services to the organization of schools, school systems, and education-related agencies within the country and cultures in which they practice. Special educators are aware of how their own and others' attitudes, behaviors, and ways of communicating can influence their practice, and use this knowledge as a foundation to inform their own personal understandings and philosophies of special education.

Special educators engage in professional activities and participate actively in professional learning communities that benefit individuals with exceptionalities, their families, colleagues, and their own professional growth. Special educators view themselves as lifelong learners and regularly reflect on and adjust their practice, and develop and use personalized professional development plans. Special educators plan and engage in activities that foster their professional growth and keep them current with evidence-based practices. Special educators also know how to recognize their own skill limits and practice within them. 


\subsection{Advancement of the Profession}

Professionals are members of one or more professional associations that have a degree of autonomy in control of the work of the profession and the conditions that contextualize it. Active involvement in professional associations reinforces several aspects of professionalism. Involvement can contribute to the specialized body of knowledge, information about evidence-based practice, and maintenance of competence. Such associations can also increase awareness of and compliance with professional and ethical standards. Ongoing networking and mentoring further reinforces the professionalism of the group. Finally, involvement provides professional identity among colleagues and the public at large.

\subsection{Need for Self-Governance and Leadership Roles}

Professional's public trust and confidence is based on the demonstrated capacity to provide safe and effective service. The public has opinions on the trustworthiness of professions and institutions, which determines how they interact with and rely upon them. However, there have been attacks on educators.

These attacks can degrade the publics' trust of professional educators. In spite of these attacks, the public has maintained a high trust for special education professionals. Trust is carefully conferred and must be protected. Special educators' ability to serve the public and clients is wholly dependent upon their trust in their professional judgment and their ethics.

\subsection{Accountable To Multiple Constituents}

Professional special educators are accountable to different constituents and publics. Of these constituents, the relationship that the special educator has with the student or employer is especially influential on specialized autonomy and work context.

Employers prefer to control when, to whom, and under what conditions the employees provide services. Employers also judge the performance of employees and strongly influence standards, ethics, and competence that may affect a professional employee's ability to maintain highly professional behavior. Thus, the characteristics that identify a professional, autonomy, commitment, identification, and ethics, may be affected because the professional answers directly to the employer and less frequently to the parents, individuals with exceptionalities, and a professional association. Whether special education professionals are employers, supervisors, clients, or employees, they are aware that there may be competing demands to be considered. The CEC Guidelines for Ethical Practice may be consulted when considering the various demands of constituents.

Professionals actively influence the context in which they practice at the school, local, state and national levels.

The distribution of power, authority, and control in schools is one of the most important issues in contemporary education research and policy. Indeed, this issue lies at the crux of many current reformsteacher empowerment, site-based management, and related forms of school decentralization [20]. Although the importance of the distribution of power in school systems has become increasingly recognized among both education researchers and policymakers, this has not resulted in the prevalence of high levels of teacher empowerment in schools. The results show, for example, that in few schools did principals report their faculties to have as much decision-making authority and influence over key educational issues as they themselves had. This finding raises questions about how much delegation of decision-making to teachers has actually occurred in recent years, and why.

\section{Conclusion}

Inclusion for individuals with disabilities has been a compelling educational policy issue for some time now. However, the recent UNESCO report, Fixing Broken Promises, makes clear that children with disabilities are too often critically underserved or excluded from education altogether because systems do not have the resources including special education professionals. For far too long policymakers have opted for cheap quick fix policies and even strategies of blame.

The effective inclusion of individuals with exceptionalities in schools and to learning is a complex policy issue that requires policymakers to contextualize the issue of inclusion within a more fundamental focus on the infrastructure of education as a profession. An essential component of this infrastructure is well-prepared and qualified professional special educators from a variety of specializations with the appropriate resources and professional freedom to personalize the appropriate instruction and supports for each individual with an exceptionality.

If policymaking bodies genuinely desire effective inclusion of individuals with exceptionalities in learning and school environments, they must refocus their reform efforts toward supporting special 
educators establishing special education as a mature profession.

Professionalism in special education is the catalyst for optimal learning of children with exceptionalities, and should be the overriding guide for policy issues such as inclusion.

Over two decades of quick fix policies and strategies of blame (cite) make clear that governmental policy bodies must refocus their reform efforts toward supporting special educators establishing special education as a mature profession that collegially advances the science of the profession and the interdisciplinary practice of effective interventions. While there are multiple challenges, continued progress toward professionalism in special education is possible and necessary.

\section{References}

[1]UNESCO World Conference on Education for All: Meetings the Basic Learning Needs. (1990). World Declaration on the Education for All and A Framework for Action to Meet Basic Learning Needs. UNESCO: Jomtien, Thailand;http://unesdoc.unesco.org/images/0009/000975/09 7552e.pdf. (May 15, 2015).

[2]UNESCO Institute for Statistics. (2015). Fixing Broken Promises: Findings from the Global Initiative on Out- ofSchool Children. UNESCO Institute for Statistics: Quebec, CA.

[3]Merriam-Webster (2011). Merriam-Webster's Collegiate Dictionary, 11th Edition. Merriam-Webster, Inc.: Spring, MA.

[4]MedicineNet.com. (2002). Flexner Report: Birth Of ModernMedicalEducation; http://www.medicinenet.com/scr ipt/main/art.asp?articlekey=8795 (May 31, 2015).

[5]Kincaid, Shannon, Pecorino, Philip. (2004). The Profession of Education: Responsibilities, Ethics and Pedagogic Experimentation. Queensborough Community College, City University of New York: New York; http://www.qcc.cuny.edu/SocialSciences/ppecorino/Profess ion-Education-text.html (May 31, 2015).

[6]Ravitch, D., (2003) A Brief History of Teacher Professionalism. White House Conference on Preparing Tomorrow'sTeachers; http://www2.ed.gov/print/admins/tchr qual/learn/preparingteachersconference/ravitch.html (May 31, 2015).

[7]Council for Exceptional Children. (2009). What every special educator must know: Ethics, standards, and guidelines (6th ed. revised). Arlington, VA: Author.

[8]Wise, A., (2005). Establishing Teaching as a Profession: The Essential Role of Professional Accreditation. Journal of Teacher Education September/October 2005 56: 318-331.

[9]Taylor, Gerald and Robert Runté, eds. Thinking About Teaching: An Introduction. Toronto: Harcourt Brace, 1995. [10]Darling-Hammond, L., \& Hudson, L. (1990). Precollege science and mathematics teachers: Supply demand and quality. In C. B. Cazden, (Ed.) Review of Research in Education, 16 (pp. 223-264). Washington, D. C.: American Educational Research Association.
[11]Darling-Hammond, L. (1984). Beyond the Commission Reports: The Coming Crisis in Teaching. Santa Monica, CA: Rand Corporation.

[12]Darling-Hammond, Linda. (2012). Powerful teacher education: Lessons from exemplary programs. John Wiley \& Sons, 448 pages

[13]Milner, H.R. (2013). Policy Reforms and Deprofessionalization of Teaching. Boulder, CO: National EducationPolicyCenter.http://nepc.colorado.edu/publication /policy-reforms-deprofessionalization. (January 15, 2015). [14]Rosenberg, M. S., \& Sindelar, P. T. (2005). The proliferation of alternative routes to certification in special education: A critical review of the literature. Journal of Special Education 39: 117-127

[15]Boe, E. E., Cook, L. H., \& Sunderland, R. J. (2008). Teacher turnover in special and general education: Exit attrition, teaching area transfer, and school migration. Exceptional Children, 75(1), 7-31.

[16]Imazeki, J. \& Goe, L. (2009). The Distribution of Highly Qualified, Experienced Teachers: Challenges and Opportunities. TQ Research \& Policy Brief. Washington, DC: National Comprehensive Center for Teacher Quality. [17]Gersten, R., Keating, T., Yovanoff, P., \& Harniss, M. (2001 cited as 2003). Working in special education: Factors that enhance special educators' intent to stay. Exceptional Children (67)4 pp. 549-567. And Billingsley, B.S. (2005 cited as 2006).

[18]Kumashiro, K. (2012). Bad Teacher! How Blaming Teachers Distorts the Bigger Picture. Teachers College Press: New York.

[19]Nancy Sato and Milbrey W. McLaughlin, "Context Matters: Teaching in Japan and in the United States," Phi Delta Kappan, January 1992, pp. 359-66. and James W. Stigler and Harold W. Stevenson, "How Asian Teachers Polish Each Lesson to Perfection," American Educator, spring 1991, pp. 12-47.

[20]Ingersoll, R.M., Alsalam N., Quinn, P., and Bobbitt S., Teacher Professionalization And Teacher Commitment: A Multilevel Analysis. 